\title{
IMI's teaching design, feedback system and its localization
}

\section{Tingting Wen, Xuexin Zhang}

Tingting Wen, Xuexin Zhang, "IMl's teaching design, feedback system and its localization," Proc. SPIE 10452, 14th Conference on Education and Training in Optics and Photonics: ETOP 2017, 1045239 (16 August 2017); doi: $10.1117 / 12.2270965$

SDIE Event: 14th Conference on Education and Training in Optics and Photonics, ETOP 2017, 2017, Hangzhou, China 


\title{
IMI's Teaching Design, Feedback System and its Localization
}

\author{
Tingting Wen ${ }^{1} \quad$ Xuexin Zhang ${ }^{2}$
}

1 Shanghai Communications Polytechnic, Email: dolphintyty@163.com

2 Fudan University, Shanghai, Email: xuexinzhang@fudan.edu.cn

\begin{abstract}
In Britain, the Institute of the Motor Industry (IMI) sets the National Occupational Standards for all sectors of the automotive industry. The IMI certificate and associated training programs are well recognized for its high quality both in the United Kingdom (UK) and internationally.

Using China's first groups studying IMI Level 3 certificate for teachers and Level 2 certificate for students as a sample, we analyzed the seven central aspects in IMI teaching, namely, assessment standard, environment, method, content, procedure, quality control and feedback. We then proposed strategies and guidelines for its localization in China, which would be particularly important for the establishment and expansion of IMI centers.
\end{abstract}

Key words: IMI teaching design; feedback system; localization; assessment; strategies

Note: Supported by Shanghai Teaching and Research Office of Municipal Education Committee

\section{About IMI}

Founded in 1920, the Institute of the Motor Industry (IMI) provides a wide range of international qualifications to accommodate all aspects of the Automotive Industry ${ }^{[1]}$. The IMI certificate and associated training programs are well recognized for its high quality and international standard. Therefore, Shanghai Communications School and IMI established the first IMI LV2 center in eastern part of China; subsequently on Dec 12thit has built the first Level 3 IMI center in Pudong. With the support of Shanghai Municipal Education Commission, 14 teachers from different automotive schools went to the UK for4 weeks training at Emtec Colleges Limited, Ruddington, Nottingham. The author witnessed the whole assessment process and had an in-depth investigation of the IMI LV2 students' group as well.

14th Conference on Education and Training in Optics and Photonics: ETOP 2017, edited by Xu Liu,

Xi-Cheng Zhang, Proc. of SPIE Vol. 10452, 1045239 - () 2017 ICO, IEEE, OSA, SPIE

CCC code: $0277-786 X / 17 / \$ 18 \cdot$ doi: $10.1117 / 12.2270965$ 


\section{IMI's teaching design}

\subsection{Assessment standard}

The assessment reflects real working practice in enterprise. Therefore it is a practical, timed, skills assessment with faults placed on genuine working vehicles and it is the responsibility of the candidate to diagnose and rectify the fault. It is the assessor's responsibility to ensure that IMI standards are maintained throughout the assessment and at the end of the assessment will make a judgment, Passed or Referred. First of all, a pass is a pass. Second, subjectively speaking referred is similar to failed, but it is more humane. Even if you are referred this time, IMI will show you the chance for the next opportunity with your efforts. At the very beginning, half of the teachers were referred and finally all of them passed all the assessment. This is very helpful for building their confidence and promoting their personal growth, which can't be done by just failing them.

(Note: Weather they have Passed or been Referred Feedback is always given from the assessor in response to their performance. This sets the standard and tone for the next assessment)

Currently in China, the assessment standard of grade test is purely technical. During the test, the assessor and candidate usually don't communicate with each other. Basically, it covers all scopes in automobile repairs. Technically speaking, the standard is even higher than IMI's. IMI's assessment is more like an employee who are being assessed by a technical manager in enterprise, to prove that he or she is comprehensively competent to repair a motor vehicle. The system in China is more like a process, to judge employee's level and competence: then prove their knowledge to the master.

\subsection{Assessment environment}

IMI pays great attention to the environment and health and safety which could be shown in the following six aspects:

(1) Wastes materials are dealt with in accordance with college's policy and procedure whilst meeting local and national Health and Safety requirements (legislation/law) 
(2) Personal protection equipment(PPE)is really strict. All protective equipment is provided by the college in line with Health and Safety legislation.

- Safety hat should be worn when working under the car

- Goggles are required when looking up

- Cotton gloves are needed or the use of a barrier cream, to protect the hands and skin

- Rubber gloves used with oil's and lubricants

- Cleaner jobs will have bare hands and wear no gloves

- Location with temperature concerns should be considered i.e. engine hot, coolant hot, oils hot

- There is equipment for cleaning eyes on site, which is rarely seen in China. It is graphic and clear, so even non-English speakers could understand.

- $\quad$ First Aid boxes are close by in the event of an accident

(Note: Eye cleaning station and First Aid are in support and does not replace a doctor or visit to the hospital)

(3) Tools for recycling waste oil further support legislation in relation to Health and Safety and should be recycled systematically. In the training, there is tool called oil drainer with a handle and small opening and the oil could flow out conveniently. In China, it is just a basin without any sound details.

(4) Equipment for cleaning is well prepared. Dirt or impurities will fall off each time when knocking on the chassis. There are special zones for brooms and mops, which will motivate people to clean the workshop. All tools and equipment should be stored correctly and in their preferred location.

Equipment for exhaust emission (exhaust gases) is neglected. It is only needed when the engine is started. This equipment is connected to the exhaust pipe and redirects the exhaust gases away from an enclosed area, (exhaust gases are poisonous and bad for the environment). In the UK this equipment conforms to legislation and removes the gases via extraction. The trainees are required to use it every time when they start the vehicle which is up the required standard.

(5) Storage and battery management is very careful. There are requirements for dealing with the correct storage of batteries in a well ventilated area. All the abandoned batteries are recycled in a regulated area. There is working benches specially made of rubber for insulation. Good batteries should be charged independently and adjust to the correct time in case of damage or explosion which may have pollution of the environmental issues. 
(6) Equipment for fire protection is complete. There are 4 different types of fire-extinguisher Foam, Water, Powder and Carbon Dioxide (CO2), these are designed to deal with different types of fire, see below:

CATEGORY

- A - Flammable Solids

- B - Flammable Liquids

- C - Flammable Gases

- E - Electrical Hazards

\subsection{Assessment method}

(1) The assessors pay attention to details. IMI assessment places a priority on Health and Safety of the individual throughout their assessment and cares very much. For example, a big shout (CLEAR!) before using the vehicle lifts / ramps to warn other people in the vicinity of this dangerous piece of equipment being used.

Another good example of Health and Safety is to wear a hard hat and goggles whilst working under the vehicle, which is often ignored in China. Teachers usually don't wear it when using the vehicle lift / ramp. It is considered not careful enough when they teach the students. If it could be cared, the passing rate would be higher. Besides personal experience, internet is useful. Suppose there is an assessment of chassis tomorrow, the candidates could collect information about the possible faults and have a discussion first for better diagnosis.

(2) The IMI has a high standard with a quality provision whilst adhering to the manufacturers specifications and technical data. For example, there is standard torque for nuts and bolts, this must be used in accordance and reflect real working practice.

(3) The candidates carryout assessments, reflecting real working practice, with real faults placed on the vehicle that represent a possible genuine customer fault.

Part of the IMI training is how to use the tools intelligently, correctly and for the correct purpose. It will make the job easier by using it smartly. The tool kit should be allocated in the same side when working on one side of the car. Details should be paid, like turn the torque wrench to zero after using it. Turn the steering a little bit outwards so there is more space when removing the brake disc. If it is too difficult to remove the bolt on the 
bottom, deal with the upper one first to make room for clearance. Try to think out of the box and break the mindset to remove the attaching parts. Put the frequently-used tools on the kit instead of wasting time in fetching them again and again. Push the torque wrench from top-down, not from bottom-up to save energy and take care of your back.

(4) Stay calm and be relaxed during the assessment process. In some cases, when the fault is complicated and it is possible to go astray. Keep calm and analyze the cause, and eliminate all the possible causes. The assessors of IMI are very friendly, while the assessors in China are high above. It is not easy to form an equal relationship. However, the candidates can discuss with the IMI assessor during the process, yet it will be serious arguing with the assessor in China.

(5) Make it real when setting the fault. The content of the IMI assessment is closer to the actual life. The type of the vehicle will change, too. In this case, the assessor of IMI is very positive about the diagnosis of the candidates. They will provide some enlightening indication in resolving the tension of the candidates. Faults that IMI set are reasonably common, more close to the actual fault that will occur, while the faults are very tricky in the competition of China.

(6) The IMI assessment focus on the process while we focus more on the result. Due to the different situation of the two countries, both have advantages and disadvantages. In China, the assessment is one-time procedure. The candidates have to complete all the items within one day. It is a great pressure for the candidates because the assessor is not only an invigilator, but also like a policeman. The candidates have to go through all the IMI's assessment and make appointments with the assessor for each assignment. If one assignment is referred, the candidates can't go to the next one. The characteristic of IMI is that the assessor is more like a mentor and a guide. He or she has the judgment. If it is up to IMI standard, it will be a pass. In China, we pay more attention to the knowledge. IMI is step by step.

(7) The assignment is displayed well in the task sheets. The assignment is very close to the assessment. By writing down the task sheets, a candidate can complete a practical task equivalently. Finishing the assignment is equal to completing an essay. 


\subsection{Assessment content}

There are two parts of the assessment, one is theoretical part and the other is practical part. The theoretical part is an online test with a pass rate of $80 \%$, on engines, transmission, chassis and electrical areas. There are 6 Written Assessments / Assignments the candidate must pass with a $60 \%$ pass rate. The assessment content covers 15 workshop practical assessments. Compared to IMI, there is some disadvantage of the domestic assessment. For instance, the item is limited and the skills are not applicable in real life. Some items are restricted on cars that can't be started. In IMI's assessment, the car should be driven, which will empower the candidates and upgrade their ability. In domestic assessment, even the candidates found the fault in China, if the car can't work properly, the candidates are lack of fulfillment.

\subsection{Assessment procedure}

With the Level 3 IMI, the candidates have to complete the knowledge part first, while domestic assessment carries out both theory and practice together. The item of IMI's assessment is completed after it is taught, paying attention on the communication with the assessor, tool preparation and its application in practice. The domestic situation is that the number of assessors is small but there are too many candidates. The total assessing time may be almost the same, but the number of domestic items within a particular time period is larger.

\subsection{Quality control}

(1) Safety is priority. The assessors should be familiar with all the items and make sure the safety when the candidates operate in the workshop. If they put the tools freely, the assessor should realize that and remind them. The assessor should take sample. When the candidates do the wrong things, the assessor should take photos and display it in summary so as to reinforce the impression.

(2) Validation of the assessment must meet the IMI criteria and standards; this is confirmed by the assessors signature. In many places within China, stamp is related to qualification. However, IMI approves by signature. If it is up to the standard, the assessor makes the judgment there and then. 
There is supervisor above the assessor an Internal Quality Assurer (IQA). The IQA will schedule a visit twice a year. The first one is a formative assessment checking the assessor's decisions and associated documentation, half way through the program. The second one is at the end a summative assessment, again checking assessor's work and associated documentation. At the same time, the IQA assesses the assessor who assesses the candidates. The IQA monitors the assessor and candidate's progress and work. This is to ensure that the IMI standards and criteria are met and maintained with a quality provision and demonstrating best practice. If the candidates fail, the assessor should take responsibility and plan and schedule a new assessment.

\subsection{Feedback}

With the Level 3IMIthe feedback is personal and reflects the assessment process. This will point out the strength of the candidates, protecting their self-esteem and propose constructive suggestions according to their personality, capability and outcome of the assessment. One technique used is reverse psychology and they ask the candidates to assume if they were the assessor, what would you do..., this promotes self-evaluation and thinking in a different way. They discuss what has been done right and what needs to be modified and how with a suggested plan they can improve. This supports the assessor's growth, self-esteem and confidence. In fact, it is very similar to psychological counseling.

\section{Strategies and suggestions}

\subsection{Set up "teaching factory" based on modern apprenticeship}

We can make the theoretical teaching more professional. Treat the students as social human beings. Before they actually go to society, teach them the way of working and gradually help them with adaptability in the process of transferring from a student to an employee. Meanwhile, quality control is not just on individual but on the whole center which have to undergo an assessment twice a year from the External Quality Assurer (EQA) and requires honesty from the center.

\subsection{Add more on-site material besides textbooks}

Taking photos of the candidates when they perform well and badly is a good visual aid and supports the 
feedback process very well. This is displayed and it reminds the candidates about their performance good and bad. Rather than just explaining verbally it allows the candidates to see and discover for themselves what is good and bad practice; let them propose the correct way. The material from the workshop represents real working practice, which is vivid and real.

\subsection{Use the tools reasonably}

Once the tools have been used, rather than clean and put them away, the tools can be placed in a convenient place ready to use again. This avoids moving back and forth and saves time which makes the whole process a little more efficient. Good and abstract professional habits will benefit the candidates within in their career.

\subsection{Customized re-sit}

Take the abstract weak points of the candidates into consideration. It is not appropriate for them to take everything again in their re-sit. Focus on what they really don't understand, so that they will realize the improvement after the re-sit and will not be afraid of it because they actually upgrade their skills from it. This means that the re-sit is tailored for the candidates ${ }^{[2]}$.

\subsection{Invent useful teaching tools}

It should provide clear instruction descriptively, interesting in design and enhance the interaction among candidates. Help them summarize what they have learnt and can be used for their self-reflection of the knowledge and skills. What's more, it can be used as reference for teachers in the future.

\subsection{Establish equal system for suing and complaints}

If the candidate is not satisfied with the assessor in China, he or she could apply to the relevant functional department. However, the candidates should go step by step in IMI because the signature of the assessor has authority. IMI is based on honesty. If the candidate is referred, he or she could make appointments and retake it in 
some other time. After completing all the items, IMI will send external supervisor to check the portfolio. If there is no problem, he or she could apply for the certificate. During the external supervision, some candidates will be reassessed by rate. If it is a referred, it will affect the authority of the internal supervisor or even worse, get fired. Therefore, the authority of the assessor is taken seriously. In China, the assessment is supported by system. In Shanghai, qualifications of all levels should be carried out in qualified workshop and stations. The department of human resource and social security will arrange assessors (all items within one day). Each assessor can only be responsible for one item and there are cameras. All the scores given by the assessors are separately. The department will check the scores after the assessment. In this case, the candidates are not able to know the result immediately. There is also supervisor on site. If the candidates fail, the organization that takes in charge of the training will inform the candidates.

\section{Conclusion}

In Summary the IMI has its advantages in training and course design from the above seven aspects. It is more than just a certificate. The teaching design takes candidates' personal requirement into consideration. It has special characteristics in quality control and feedback. The standard is strictly held, which is a great help for improving the knowledge and skills of the candidates. If we could learn from the teaching model, it will be particularly important for the establishment and expansion as well as localization of IMI centers in China. This kind of approach sets out to meet the divide with the current skills gap within this industry. The educational comparison is a bond for deeper communication among countries ${ }^{[3]}$, which will be a great help to understand the difference and therefore speed up the procedure of localization.

\section{Reference}

[1] $\underline{\text { http://www.theimi.org.uk/about-institute-motor-industry-imi }}$

[2]Wang Jiayi, Xu Jieying, Comparison of Teaching Research Model at Home and Abroad, Comparative Education Review, 1997 (5): 43-47

[3]Zhou Zhuang, The Comparative Research of Physics Experiments' Education in High School at Home and Abroad, Shandong Normal University Dissertation for the Degree of Master, 2012 